PNL-2749 SUPP, Rev. 1

\title{
Operational Safety Requirements \\ Neutron Multiplier \\ Facility in 329 Building
}

\author{
E. A. Lepel
}

October 1992

Prepared for the U.S. Department of Energy under Contract DE-AC06-76RLO 1830

Pacific Northwest Laboratory

Operated for the U.S. Department of Energy by Battelle Memorial Institute 


\title{
DISCLAIMER
}

This repor was prepared as an account of work sponsored by an agency of the United States Government. Neither the United States Covernment nor any agency thereof, nor Battelle Mernoriai Institute, nor any of their employees, makes any warranty, expressed or implied, or assumes any legal liability or responsibility for the accuracy, completeness, or usefulness of any information, apparatus, product, or process disclosed, or represents that its use would not infringe privately owned rights. Reference herein to any specific commercial product, process, or service by trade name, trademark, manufacturer, or otherwise does not necessarily constitute or imply its endorsement, recommendation, or favoring by the United States Covernment or any agency thereof, or Battefle Memorial Institute. The views and opinions of authors expressed herein do not necessarily state or reflect those of the United States Government or any agency thereof.

\author{
PACIFIC NORTHWEST LABORATORY \\ operated by \\ BATTELLE MEMORIAL INSTITUTE \\ for the \\ UNITED STATES DEPARTMENT OF ENERGY \\ under Contract DE-ACO6-76RLO 1830
}


PNL-2749 SUPP, Rev.1

33679000491805

Operational Safety Requirements

Neutron Multiplier Facility in 329 Building

E. A. Lepel

October 1992

Prepared for the U.S. Department of Energy under Contract DE-AC06-76RLO 1830

Pacific Northwest Laboratory

Richland, Washington 99352 



\section{Foreword}

Operational safety requirements (OSRs) for the Neutron Multiplier Facility, 329 Building, were first issued in October 1981 and were amended in 1989 and 1991. This revised document is taken from each of the source documents, and includes only those items that are currently in effect. The glossary was added as part of the 1991 revision to correlate nomenclature in older versions to the nomenclature in effect today. Approved glossary terms that do not appear in the updated OSR document are not included in this revision.

Appendix A, "Operations Safety Requirements Road Map" has been deleted from this revision. The former Appendix B is now cited as the Appendix.

For a complete history of the original OSRs and the revisions, please see the original documents listed below in chronological order.

Richey, C. R., Supplement to Safety Analysis Report for the Neutron Multiplier Facility, 329 Building, Operations Safety Requirements, PNL-2749 SUPP, October 1981, Pacific Northwest Laboratory, Richland, Washington.

Chikalla, T. D., letter to J. J. Sutey, Operations Safety Requirements (OSRs) - 329 Neutron Multiplier Facility (NMF), September 23, 1988, Pacific Northwest Laboratory, Richland, Washington.

Chikalla, T. D., letter to J. J. Sutey, Operations Safety Requirements (OSRs) - 329 Neutron Multiplier Facility (NMF), April 6, 1989, Pacific Northwest Laboratory, Richland, Washington.

Sutey, J. J., letter to Director, PNL, Approval of Revised Operations Safety Requirements (OSR) for 329 Facility, August 9, 1989, U. S. Department of Energy, Richland Operations Office, Richland, Washington.

Laity, W. W., letter to J. J. Sutey, Operarional Safety Requiremenss (OSRs) - 329 Building Neutron Multiplier Facility, February 19, 1991, Pacific Northwest Laboratory, Richland, Washington.

Sutey, J. J., letter to Director, PNL, Approwal of Operational Safety Requirements (OSR) - 329 Building Neutron Multiplier Facility, May 20, 1991, U. S. Department of Energy, Richland Operations Office, Richland, Washington. 



\section{Contents}

Foreword $\ldots \ldots \ldots \ldots \ldots \ldots \ldots \ldots \ldots \ldots \ldots \ldots \ldots \ldots \ldots \ldots \ldots \ldots \ldots$

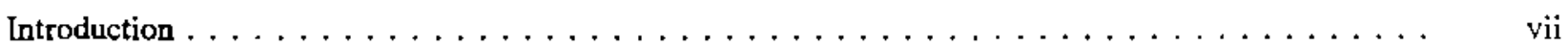

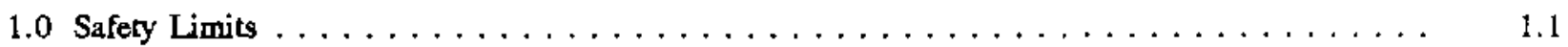

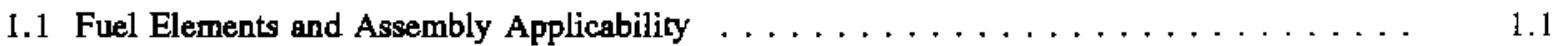

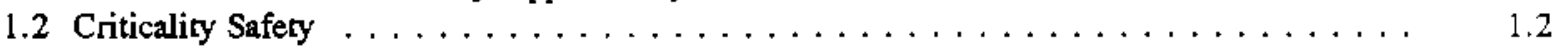

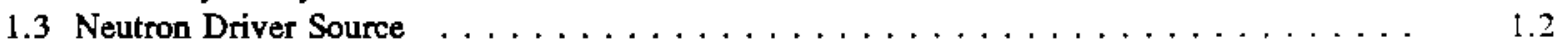

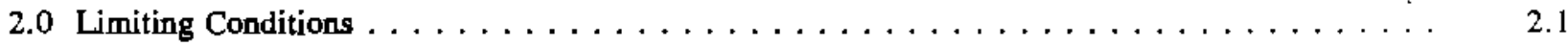

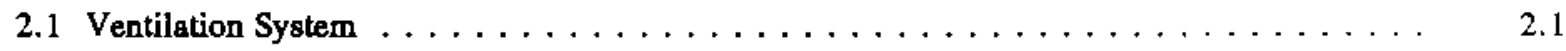

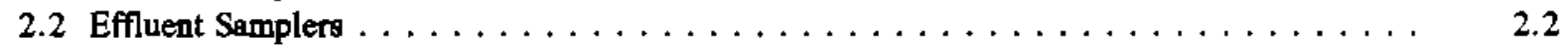

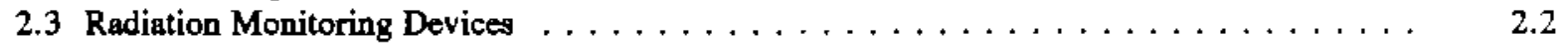

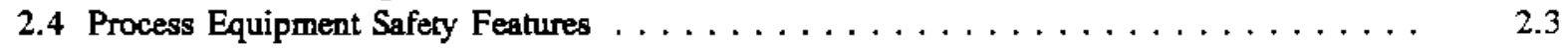

2.5 Emergency Alarms and Lighting $\ldots \ldots \ldots \ldots \ldots \ldots \ldots \ldots \ldots \ldots \ldots \ldots \ldots$

3.0 Surveillance Requirements $\ldots \ldots \ldots \ldots \ldots \ldots \ldots \ldots \ldots \ldots \ldots \ldots \ldots \ldots$

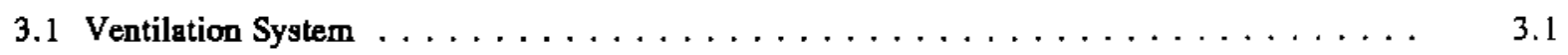

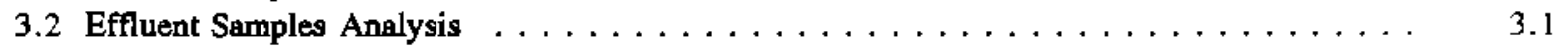

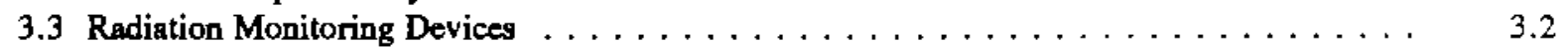

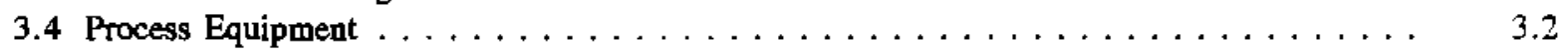

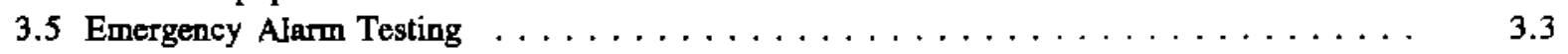

4.0 Equipment Design Controls $\ldots \ldots \ldots \ldots \ldots \ldots \ldots \ldots \ldots \ldots \ldots \ldots \ldots \ldots$

4.1 Design Changes $\ldots \ldots \ldots \ldots \ldots \ldots \ldots \ldots \ldots \ldots \ldots \ldots \ldots \ldots \ldots \ldots \ldots$

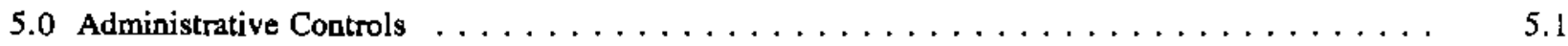

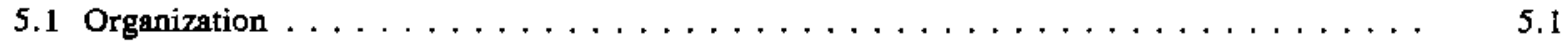

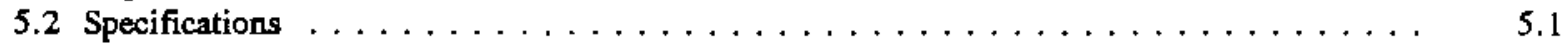

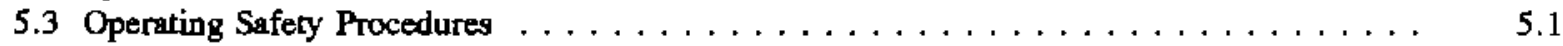

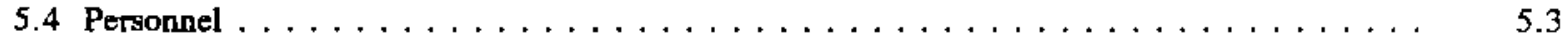

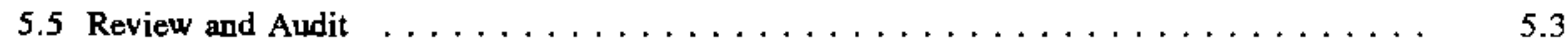

5.6 Administrative Action in the Event an OSR is Not Met $\ldots \ldots \ldots \ldots \ldots \ldots \ldots \ldots$

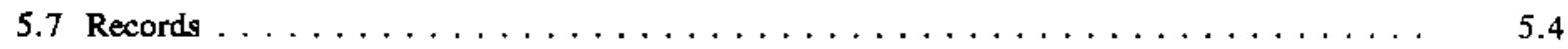

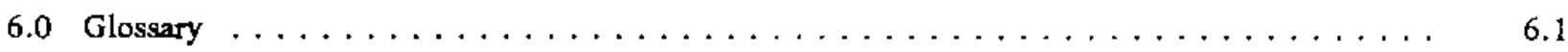

Appendix - Neutron Multiplier Fuel Specifications $\ldots \ldots \ldots \ldots \ldots \ldots \ldots \ldots \ldots \ldots$ A. I 



\section{Introduction}

The operational safety requirements (OSRs) presented in this report define the conditions, safe boundaries and management control needed for safely operating the Neutron Multiplier Facility in the 329 Building Annex. Technical bases for the OSRs were developed and discussed in Safety Analysis Report for the Neutron Multiplier Facility, 329 Building (SAR). ${ }^{\text {(a) }}$

The safety requirements are organized in five sections:

1. Safety Limits are safety-related process variables that are observable and measurable.

2. Limiting Conditions cover a) equipment and b) technical conditions and characteristics of the facility and operations necessary for continued safe operation.

3. Surveillance Requirements prescribe the requirements for checking systems and components that are essential to safety.

4. Equipment Design Controls require that changes to process equipment and systems be independently checked and approved to ensure that the changes will have no adverse effect on safety.

5. Administrative Controls describe and discuss the organization and administrative systems and procedures to be used for safe operation of the facility.

Details of the implementation of the OSRs are prescribed by Pacific Northwest Laboratory (PNL) internal documents such as Criticality Safety Specifications and Radjation Work Permits.

Any change in operations or equipment that introduces an unreviewed safety question or that significantly increases the probability or consequences of an accident discussed in the SAR shall require an addendum to the SAR. A corresponding addendum and/or modification to the OSRs shall also be required.

(a) Rieck, H. G. 1978. Safety Analysis Report for the Neutron Multiplier Facility, 329 Building, PNL-2749, Pacific Northwest Laboratory, Richland, Washington 99352. 



\section{Section 1 - Safety Limits}

Safety limits that apply to fuel loadings, irradiation samples, and neutron driver sources and their effect on criticality and radiological safety or operating the Neutron Multiplier are described below.

\subsection{Fuel Elements and Assembly Applicability}

Applicability

Objective

Requirements

Corrective Action

Basis
This requirement defines the fuel assembly loaded into the Neutron Multiplier.

The objective of these requirements is to preclude the loading of fuel assemblies into the Neutron Multiplier that could reduce the safety margin from that described in the SAR.

1.1.1 The Neutroo Multiplier fuel assembly shall be loaded in an annular hexagonal array with the fuel elements on a 0.60 inch center-to-center spacing.

1.1.2 Only Neutron Multiplier fuel elements shall be used in the Neutron Multiplier. These fuel elements are characterized by the specifications given in the Appendix.

1.1.3 Perform any fuel loading, unloading, or other fuel changes under supervision of the senior engineer in nuclear safety, or authorized delegate. (Revised 5/20/91)

If the fuel loading in the Neutron Multiplier does not meet requirements 1.1.1 through 1.1.3, operations with the Neutron Multiplier shall be halted promptly. Recovery and reporting requirements specified in Section 5.6 and in PNL-MA-25, Criticality Safery, shall be initiated.

The safety analyses pertaining to criticality safety presented in the SAR were based upon extensive experimental testing at the PNL Critical Mass Laboratory using the same lattice spacing and fuel rods loaded in the Neutron Multiplier.

Use of different spacings or fuel types would be unevaluated so the margin of subcriticality of the multiplier would require further calculation and consideration by a Recovery Committee before initiation of any action whatsoever.

The status of the Critical Mass Laboratory is uncertain and in the future tbere may not be a designated manager of the Critical Mass Laboratory. (Added $5 / 20 / 91$ ) 


\subsection{Criticality Safety}

Applicability

Objective

Requirements

Corrective Action

Basis
This requircment applies to receiving and handling at the Neutron Multiplier facility and the loading into the Neutron Multiplier materials that could compromise criticality safety.

The objective is to provide limitations on material for ensuring criticality safety in the operation of the Neutron Multiplier.

1.2.1 The total fuel element loading for the Neutron Multiplier is limited to 257 fuel elements.

1.2.2 Fissionable material within the Neutron Multiplier facility is limited to the fuel loading, sealed sources to drive the Neutron Multiplier, and a maximum of $\mathbf{4} \mathbf{g}$ fissile material in the form of irradiation samples in excess of the fuel loading.

1.2.3 The amount of beryllium permitted within the Neutron Multiplier facility is limited to $5 \mathrm{~g}$.

1.2.4 $\mathrm{D}_{2} \mathrm{O}$ in excess of that occurring naturally in water is not allowed within the Neutron Multiplier facility.

1.2.5 The total amount of carbon loaded into the Neutron Multiplier is limited to $715 \mathrm{~g}$.

If requirements 1.2.1 through 1.2.5 are exceeded, operations with the Neutron Multiplier shall be halted promptly. Recovery and reporting requirements specified in Section 5.6 and in PNL-MA-25, Criticality Safery, shall be initiated.

Experimental testing at the PNL Critical Mass Laboratory with the Neutron Multiplier lattice plates demonstrated that the maximum credible neutron multiplication factor $\left(k_{00}\right)$ for the Neutron Multiplier would not exceed 0.993 with the fuel loading and irradiation samples restricted to the limits specified by requirements $1.1 .1,1.1 .2,1.2 .1,1.2 .2,1.2 .3,1.2 .4$, and 1.2 .5 .

\subsection{Neutron Driver Source}

Applicability

Objective

Requirement

Corrective Action
This requirement applies to the neutron driver source for the Neutron Multiplier.

The objective of this requirement is to restrict the neutron driver source to a source strength for which the radiological safety of the Neutron Multiplier operation has been analyzed.

1.3.1 The total amount of ${ }^{252} \mathrm{Cf}$ in the driver source sball be limited to 100 milligrams.

If the total amount of ${ }^{252} \mathrm{Cf}$ in the driver source exceeds 100 milligrams, operations with the Neutron Multiplier sball be halted promptly. Recovery 
and reporting requirements specified in Section 5.6 and in PNL-MA-25, "Criticality Safety," shall be initiated. (Modified to add recovery action, 9/11/92).

\section{Basis}

Radiation potentials evaluated in the SAR are based upon 100 milligrams of ${ }^{212} \mathrm{C} f$ as the driver source. 


\section{Section 2 - Limiting Conditions}

Limiting conditions are discussed below for the ventilation system, effluent samplers, radiation monitors, process equipment safety features, and emergency alarms.

\subsection{Ventilation System}

Applicability

Objective

Requirements

\section{Corrective Action}

Basis
These conditions apply to the ventilation system for the Neutron Multiplier facility.

The objective is to define the operating conditions for the ventilation system to ensure that gaseous effluents from the Neutron Multiplier facility are well within DOE requirements (DOE 5400.5).

2.1.1 The gaseous effluent exhaust system for the Neutron Multiplier Facility shall include, as a minimum, one stage of HEPA filtration. When the pneumatic sampler transfer system is in use, the exhaust of the pneumatic sampler transfer system will be vented into a system that provides HEPA filtration prior to release to the environment. (Revised 8/9/89)

2.1.2 The HEPA filter element particulate removal efficiency shall be at least $99.95 \%$ for particles 0.3 to $0.8 \mu \mathrm{m}$ in size.

2.1.3 The $\Delta \mathrm{P}$ across the filter shall be $\leq 5.0$ inches of water gauge. (Revised 8/9/89)

Any time that requirement 2.1.1 is not met (equipment failure and maintenance service), insertion of material samples into the Neutron Multiplier, modification of the fuel loading, or use of the pneumatic transfer system is prohibited.

A new HEPA filter will not be installed unless it complies with the testing specified in requirements 2.1.1 through 2.1.3.

The HEPA filtration requirements ensure that average radioactive release concentrations from normal operation of the Neutron Multiplier are within PNL's ALARA goal, based on the latest DOE-approved listing of acceptable radionuclide limits. (Revised 5/20/91)

There will in effect be no change in the normal operating practice with this change [2.1.1] and there will bo no reduction in safety. The intent of this OSR is to prevent a release of radioactivo material to the environment. The HEPA filtered fume bood to which the system vents is not large enough to require $1900 \mathrm{cfm}$. At the normal required flow rate for radioactive material work (average face velocity of $150 \pm 25$ linear $\mathrm{fpm}$ ) the hood only requires $\sim 900 \mathrm{cfm}$. The $1900 \mathrm{cfm}$ number was incorrectly used. (Added 8/9/89) 
Operating with filter differential pressures outside this range [2.1.3] will not reduce the safety of operation provided the aerosol filtering efficiency and flow-rate tests are within specifications. (Added 8/9/89)

The differential pressure may be below 0.5 inches of water gauge with a properly sealed, clean filter. The aerosol test is used to show that the filter is properly removing particulate. That test is performed following installation and is repeated annually. (Added 8/9/89)

The HEPA filters are guaranteed to operate satisfactorily up to at least 10 inches of water gauge. Inability to achieve the required hood face velocity will require a filter chango well before that differential pressure is reached. That test is performed quarterly. (Added 8/9/89)

\title{
2.2 Effluent Samplers
}

\author{
Applicahility
}

Ohjective

This requirement applies to the system for sampling gaseous eftluents from the Neutron Multiplier Facility.

The objective is to define the effluent sampling system that shall be operable to ensure that operation of the Neutron Multiplier can be conducted without undue risk to onsite personnel, the public, or the environment.

\section{Requirements}

2.2.1 The gaseous effluent exhaust system for the Neutron Multiplier Facility shall be sampled continuously except for maintenance periods.

2.2.2 Prior to transfer of pool water into the sewer system, the pool water shall be sampled and analyzed to ensure compliance with the latest DOEapproved listing of acceptable radionuclide limits. (Revised 5/20/91)

Corrective Action

Should a gaseous effluent sampling system fail, action shall be taken to restore the system to operation, and portable room air samplers should be substituted promptly.

Transfer of pool water to the sewer system in violation of requirement 2.2.2 shall be halted and reporting requirements specified in Section 5.6 and in PNL-MA-8, "Waste Management \& Environmental Compliance" shall be initiated. (Modified to add recovery action 9/11/92)

Basis

Operations of the Neutron Multiplier shall be conducted such that the average radioactive release concentrations of gaseous effluents are within the latest DOE-approved listing of acceptable radionuclide limits. An air sampler in continuous operation in the exhaust system demonstrates compliance with the DOE requirements. (Revised 5/20/91)

\subsection{Radiation Monitoring Devices}

Applicability

These requirements define the radiation monitoring devices needed in the operation of the Neutron Multiplier. 
Objective

Requirements

Corrective Action

Basis
The objective is to provide a means for monitoring the neutron flux level in the Neutron Multiplier and to warn operating personnel of an inadvertent high gamma radiation field.

2.3.1 A gamma radiation monitoring device equipped with audible and visual annunciation shall be located to monitor the work area above the Neutron Multiplier pool.

2.3.2 A neutron proportional counter shall be located at the pool near the fuel assembly to monitor the neutron flux level of the Neutron Multiplier. A high neutron flux level will be signaled locally by a visual display.

If requirement 2.3.1 is not met, radiation monitoring coverage shall be provided to personnel while located in the Neutron Multiplier work area. If requirement 2.3.2 is not met, insertion of material samples into the Neutron Multiplier is prohibited. Reporting requirements specified in Section 5.6 shall be initiated and the neutron proportional counter shall be made operational before work is resumed. (Modified to add recovery action, 9/11/92).

Although the pool water above the Neutron Multiplier fuel assembly provides adequate shielding to neutrons and gamma radiation from the fission reaction and ${ }^{2 \sqrt{2}} \mathrm{Cf}$ sources, dry irradiation tubes are potential sources of personnel exposure. Manipulation of the ${ }^{252} \mathrm{Cf}$ sources and handling irradiated samples are also potential exposure sources.

A criticality condition in the Neutron Multiplier fuel assembly would be detected by the neutron proportional counter.

\subsection{Process Equipment Safety Features}

Applicability

Objective

Requirements
These requirements apply to the engineered safety features of the Neutron Multiplier and instrumentation for monitoring and safe operation of the facility.

The objective is to preciude the inadvertent loss of potentially contaminated water from the Neutron Multiplier pool and to maintain sufficient water shielding above the fuel assembly.

2.4.1 There shall be no gravity-drain connection between the Neutron Multiplier pool and the sewer system. Water shall be drained from the pool only by use of a portable pumping systern.

2.4.2 Water additions to the pool shall be made by opening a normally closed manual valve in the water make-up line. A lood controlled valve shall be in series with the manual valve to shut off the make-up water when the water level raises to 10 inches from the top of the pool.

2.4.3 Circulate the pool water through a particulate filter and an ion exchange resin column. Monitor the system operation and water quality using flow and conductivity sensors. Maintain the resistivity $\geq 3 \times 10^{4}$ 


\section{Corrective Action}

Basis obm-cm and the flow rate $\geq 4 \mathrm{gpm}$. The recirculating water system may be shut down for up to 5 days for planned and unplanned outages (e.g., power outages and system maintenance). Laboratory Safety approval is required before a shutdown of greater than 5 days. (Revised 8/9/89 \& 5/20/91)

2.4.4 Periodic radiation measurements shall monitor increases in the radiation levels of the ion exchange resin column (see Section 3.3.3).

If a gravity-drain connection between the pool and sewer system is discovered, it shall be promptly disconnected and reporting requirements specified in Section 5.6 shall be initiated.

Prompt corrective action shall be taken at any time the water level alarm is found to be inoperable.

Any time the water level in the pool raises above 10 inches from the top of the pool, prompt corrective action shall be taken to prevent pool overflow. Any time the flow or conductivity of the pool water falls outside of the respective ranges specified in requirement 2.4.3 the operation of the Neutron Multiplier shall be shut down and reporting actions specified in Section 5.6 shall be initiated. Determine the cause for the out of range readings, and take the appropriate action to correct. (Modified to add recovery action, 9/11/91).

If high radiation readings from the ion exchange unit suggest a source or fuel cladding failure has occurred, the neutron multiplier will be shut down promptly. The circulation of the pool water shall be maintained and reporting actions specified in Section 5.6 shall be initiated. Recovery action as specified in PNL-MA-6, "Radiation Protection," shall be implemented. (Modified to add recovery action, 9/11/92).

The abseace of gravity-drain connections between the pool and the sewer systems is a safeguard measure to prevent any radioactive contaminants in the pool water from being inadvertently discharged to any sewer system.

The water level in the pool gradually drops because of evaporation from the pool surface. A very liberal calculation of the evaporation under credible conditions indicates that the level would drop less than 4 inches per day. If evaporation continued for a week at the 4 inches per day rate, the loss of water shielding would increase radiation levels at the top of the pool approximately a factor of 10 to $0.1 \mathrm{mrem} / \mathrm{hr}$. Although the Safe Operating Procedures for the Neutron Multiplier require routine checking of the pool water level, the low water level alarm serves as a hackup to warn against the inadvertent loss of excessive water from the pool.

Water is added to the pool by opening a normally closed manual valve in the water make-up line. The person adding the water is required by the applicable Safe Operating Procedure to remain in the Neutron Multiplier work area during the water filling operation. The float control valve serves as a backup to prevent overflowing the pool in the event that the manual valve is inadvertently left open. 
If the fuel or ${ }^{252} \mathrm{Cf}$ source cladding is penetrated in some way, radioactive particulates would be released into the pool water. Radioactive ${ }^{24} \mathrm{Na}$ will also be produced in the Neutron Multiplier by $(n, \alpha)$ resction of fast neutrons with ${ }^{77} \mathrm{Al}$ in the thin oxide layer on the external surfaces of the fuel rods. The ${ }^{24} \mathrm{Na}$ is leached out into the pool water and will be efficiently removed along with other particulates in the water by the filter and ion exchange column. Less than $10^{-5} \mu \mathrm{Ci} / \mathrm{L}$ concentration of ${ }^{2} \mathrm{Na}$ should be present in the pool water. With the resistivity $\geq 3 \times 10^{4} \mathrm{ohm}-\mathrm{cm}$, the water purity is such that the life time expectancy for the fuel cladding is on the order of tens of years.

(Revised 8/9/89)

This OSR is intended to ensure that water purity is maintained so that potential corrosion of the fuel cladding is minimized. Since the conductivity of water decreases with decreased impurity levels, no minimum conductivity ( $3 \mu \mathrm{mhos} / \mathrm{cm}$ ) should be specified. Because the instrument currently installed measures resistivity, that term is used to eliminate the need to convert values (resistivity is the reciprocal of conductivity). Even if a fuel rupture did occur, the contamination would be retained in the pool water and would not result in a release of radioactivity to the environment. (Added 8/9/89)

Occasional short-term shutdown of the recirculating system is necessary. No provision is present in the OSR for such activities as routine maintenance or power outsges. The intent of the requirement is to maintain water purity, and analyses presented in the SAR show that water purity is not significantly impacted by short-term outages of the recirculating system. Specifically, the analyses demonstrate that no unacceptable personnel exposures or corrosion of the aluminum-clad fuel rods will occur within 5 days. (Added 5/20/91)

\subsection{Emergency Alarms and Lighting}

Applicability

Objective

Requirements

Corrective Action
This requirement applies to the availability of emergency alarms and lighting to initiate and conduct emergency actions.

The objective is to ensure that building personnel receive appropriate warning of an emergency situation and have lighting to ensure safe egress of personnel.

2.5.1 A criticality alarm system shall be operable to monitor fuel loading operations at the Neutron Multiplier.

2.5.2 A fire alarm system that also signals the 300 Area fire station shall be operable at the Neutron Multiplier Facility.

2.5.3 A building evacuation shall be made known to individuals located in the work area of the Neutron Multiplier. They are notified by building wardens (see 329 Building and Neutron Multiplier Emergency Procedure). (Revised 4/92)

Modifications to the fuel loading shall be halted at any tinse a criticality alarm system is not operable to monitor fuel loading operations. Prompt action 
shall be taken to restore any alarm systems whenever failure of an alarm is detected.

Basis

The primary purpose of the alarm systems is to immediately notify facility personnel of an emergency situation so that they may take prearranged emergency action. These alarms also notify emorgency response forces that aid is needed. Because the radiation shielding of the pool water is adequate to protect operating personnel from a criticality event, no criticality alarm system is required during normal operation of the Neutron Multiplier. However, fuel loading operations are conducted with the fuel assembly near the pool water surface. It is during these fuel loading operations that a criticality alarm system is required for personnel safety.

Emergency electric power ensures the ability to respond to an emergency situation in the event that primary electric power is lost concurrently with an emergency. Battery-powered lights are also provided to ensure safe egress of personnel in the event of total power failure. 


\section{Section 3 - Surveillance Requirements}

Surveillance requirements discussed below are related to the ventilation system, effluent analyses, radiation monitors, process equipment, and emergency alarm testing.

\subsection{Ventilation System}

Applicability

Objective

Requirement

Corrective Action

Basis
These requirements apply to the surveillance and testing of the ventilation system.

The objective is to ensure that adequate filter capability of the ventilation system is maintained. The testing of the HEPA filter will provide assurance that the Neutron Multiplier Facility can be operated without undue risk to onsite personnel, the public, or the environment.

3.1.1 The HEPA filter in the ventilation system shall be aerosol tested upon installation of a new filter and at least annually, thereafter, to determine the particle-removal efficiency. ${ }^{\left({ }^{(}\right)}$Particulate removal efficiency and $\Delta \mathrm{P}$ values are given in 2.1.1 and 2.1.3.

If an inservice HEPA filter fails to meet the testing criteria specified in requirement 3.1 .1 , action shall be taken promptly to replace the filter element.

The HEPA filter provides the final treatment of air exhausted from the Neutron Multiplier Facility and protects the environment from an accidental release of radioactive particles. Periodic testing of the filters is necessary to demonstrate their effectiveness.

\subsection{Effluent Samples Analysis}

Applicability

Objective

Requirement
These requirements apply to the frequency for analyzing samples of the gaseous and aqueous effluents from the Neutron Multiplier Facility.

The objective of these requirements is to provide assurance that the gaseous and aqueous effluents are in compliance with the latest DOE-approved listing of acceptable radionuclide limits. (Revised 5/20/91)

3.2.1 Effluent exhaust samples shall be taken from the Neutron Multiplier exhaust air and analyzed weekly.

(a) PNL Standard Maintenance Procedure, Utility Operations, "In-place Aerosol Testing of HEPA Filters," Procedure Air Balance - 3, November 19, 1991 (revised annually). 
Corrective Action

Basis
Prompt action shall be taken to restore compliance with requirement 3.2 .1 if the surveillanco checks are not made.

Data from the analysis of effluent samples are needed to demonstrate that gaseous and aqueous effluents from the Neutron Multiplier Facility are in compliance with the latest DOE-approved listing of acceptable radionuclide limits. (Revised 5/20/91)

\subsection{Radiation Monitoring Devices}

Applicability

Objective

Requirements

\author{
Corrective Action
}

Basis

\subsection{Process Equipment}

Applicability

Objective

Requirements
These surveillanco and testing requirements pertain to instruments for monitoring radiation fields associated with the operation of the Neutron Multiplier.

The objective is to ensure that instruments monitoring radiation from the Neutron Multiplier are operativo and capable of providing appropriate wamling of abnormal operating conditions.

3.3.1 The operability of the gamma monitoring device located in the work area above the Neutron Multiplier pool shall be checked each day of entry into the Neutron Multiplier work area.

3.3.2 The operability of the neutron proportional counter located in the pool near the fuel assembly is checked each day of entry into the Neutron Multiplier work area.

3.3.3 Radiation levels of the ion exchange resin column shall be measured weekly.

Prompt action shall be taken to restore compliance with requirements 3.3.1, 3.3.2 and 3.3.3 if these surveillance checks are not made.

Same basis given in Section 2.3.

These surveillance requirements pertain to the process equipment and instrumentation for monitoring the safe operation of the facility.

The objective is to provide surveillance to ensure that limiting conditions are being maintained that preclude the inadvertent loss of potentially contaminated water from the Neutron Multiplier pool and that there is sufficient water shielding above the fuel assembly.

3.4.1 During water additions to the pool, an operator shall be present and remain in the Neutron Multiplier work area until the manual valve is closed.

3.4.2 The water level in the pool shall be checked biweekly. 


\section{Corrective Action}

Basis

\subsection{Emergency Alarm Testing}

Applicability

Objective

Requirements
Corrective Action

Requirements

Corrective Action

3.4.3 Radiation dose rate from the ion exchange unit shall be checked weekly.

3.4.4 The flow and conductivity of the water in the water process system shall be checked weekly.

If requirements 3.4.1 through 3.4.4 are not met, prompt action shall be taken to restore compliance.

The presence of an operator in the work area during water additions to the pool provides backup to the float valve in preventing inadvertent overflowing of potentially contaminated water.

Routinely checking the water level of the pool permits correction for water loss due to evaporation and assurance that sufficient water shielding is maintained over the Neutron Multiplier assembly. It also provides a means for detecting excessive losses from the pool water.

If the fuel or source cladding should in some way be penetrated, the filter and ion exchange column in the water process system will efficiently remove any resulting particulate from the water. Therefore, periodically checking the radiation emanating from the filter and ion exchange column will provide a means for detecting fuel or source clad failures.

The purity of the water with the resistivity $\geq 3 \times 10^{4}$ ohm-cm should result in an extremely long life (of the order of tens of years) for the fuel and source cladding. The flow is a means of monitoring the operability of the water process system. (Revised 8/9/89)
These surveillance and testing requirements pertain to the emergency alarm systems for the 329 Neutron Multiplier Facility. (Revised 4/92)

The objective is to provide assurance that an emergency alarm is operative and capable of providing appropriate waring of an emergency situation.

3.5.1 Perform testing of the criticality alarm system (CAS) and all required maintenance within 3 months before a CAS is used under OSR 2.5.1. Repeat testing and maintenance quarterly as long as the CAS is required under OSR 2.5.1. Replace the detector heads annually with properly calibrated heads. (Revised 5/20/91)

\subsubsection{Deleted 5/20/91}

\subsubsection{Deleted 5/20/91}

If an alarm system testing requirement is not met, prompt action shall be taken to restore compliance with the requirement. 
Basis

Testing of the alarm systems provides a high degree of assurance that appropriate emergency waming and notification will be signaled to building personnol and emergency forces.

This wording [3.5.1] will provide the necessary safety requirement without relying on a document that may change at any time. (Added 5/20/91) 


\section{Section 4 - Equipment Design Controls}

Equipment design controls that apply to design changes are described below.

\subsection{Design Changes}

\section{Applicability}

Objective

Requirements

\section{Corrective Action}

Basis
This requirement is applicable to the 329 Annex and its services, and to major modifications to current or planned process equipment.

The objective is to ensure that modifications to the 329 Annex, its services, process equipment, and the design and installation of additional equipment will not have an adverse impact on safe operation.

4.1.1 Obtain approval by the operating manager of the Neutron Multiplier Facility and by cognizant safery organizations before modification of the 329 Annex and its services, and before operation of modified or newly installed facilities, services and equipment. (Revised 5/20/91)

\subsubsection{Deleted $5 / 20 / 91$}

\subsubsection{Deleted $5 / 20 / 91$}

If compliance with requirement 4.1.1 is not maintained, prompt action shall be taken to restore compliance with the requirement.

Modification of facilities, services, and process equipment is an integral part of the researcb and development work conducted in the Neutron Muitiplier Facility. A modification could affect other unrelated equipment and activities and reduce the safety of the facility. To guard against introducing unexpected and unwanted safery effects, an independent review of modifications to the facility and process equipment by the Operating Manager is required.

PNL procedures for making design changes are revised from time to time. Current requirements are described in PNL-MA-90, Design: Preparasion, Control, and Implementation, and the descriptive information does not need to be repeated here. The proposed revision replaces 4.1.1, 4.1.2 and 4.1.3. (Added 5/20/91) 



\section{Section 5 - Administrative Controls}

Requirements related to organizational controls, specifications, operating safety procedures, personnel, review and audit, and records are discussed below.

\subsection{Organization}

\subsection{Specifications}

Basis
The management organizations of PNL and of the Neutron Multiplier Facility are responsible for ensuring safe operations.

5.1.1 Management. The operational organization for the Neutron Multiplier Facility and its relationship to the PNL management structure is indicated in Figure 1. Groups that provide an independent technical review of the safe operation of the facility are also shown in the chart.

5.1.2 Facility. The Manager, Nuclear Chemistry Department, shall have line responsibility for the operation of the Neutron Multiplier Facility, including safeguarding the public and facility personnel from radiation exposure, ensuring that the conduct of the Neutron Multiplier operations are within the limits of the Operational Safety Requirements, and auditing the operations for compliance with these specifications. (Revised 5/20/91)

A Criticality Safety Specification(s) shall contain limits to maincain Neutron Multiplier Facility operations within the OSRs dealing with criticality safety. (Revised 5/20/91)

A Criticality Safety Specification is required by PNL-MA-25, Criticality Safety, for activities in a nuclear facility. However, manual revisions have outdated the references to specific sections. This proposed revision responds to the recent Tiger Team findings by tying our specifications back to the OSRs. (Added 5/20/91)

\subsection{Operating Safety Procedures}

Operating safety procedures that apply to the Neutron Multiplier Facility include: job hazard breakdowns and safe operation procedures; PNL manuals and radiation work permits; and a comprehensive building emergency plan.

\subsubsection{Job Hazard Breakdowns and Safe Operation Procedures.} Operating, maintenance and emergency procedures (e.g., Job Hazard Breakdown, Radiation Work Permit, Building Emergency Plan, NMF procedures) shall ensure that NMF operations remain within the OSRs. (Revised 5/20/91)

\subsubsection{Deleted 5/20/91}

\subsubsection{Deleted 5/20/91}




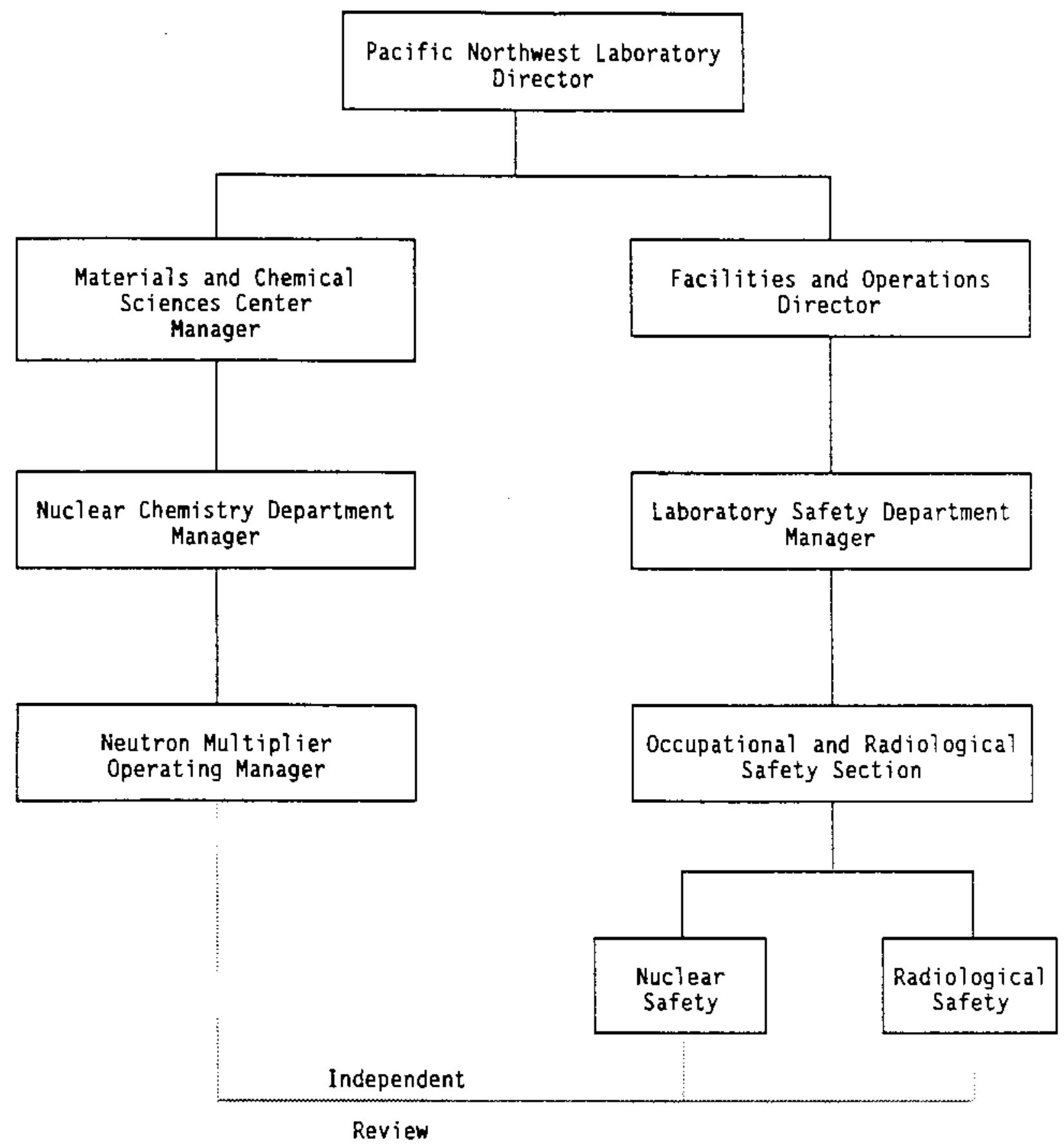

Figure 1. Operational Organization for the Neutron Multiplier Facility and its Relationship to PNL Management Structure 
Basis

\subsection{Personnel}

Basis

\subsection{Review and Audit}

Basis
Operating, maintenance and emergency procedures are required by PNL policies and procedures. This proposed revision responds to the recent Tiger Team findings by tying these documents back to the OSR. The proposed revision replaces 5.3.1, 5.3.2 and 5.3.3. (Added 5/20/91)

Training requirements and minimum personnel requirements follow.

5.4.1 Training. All personnel who work on or with projects or building systems in the 329 Neutron Multiplier shall have documented biennial training on 329-NMF OSRs. (Revised 5/20/91)

5.4.2 Minimum Personnel. Add or remove irradiation samples from the Neutron Multiplier only under the supervision of an operator. (Revised $5 / 20 / 91$ )

Compliance with the original requirement is achieved for all PNL facilities through current PNL policies and procedures. PNL has an effective system in place that accomplishes everything specified in this OSR. There is nothing additional accomplished by this OSR. (Added 5/20/91)

Instead, this OSR should address OSR training. A requirement for OSR training is being added to all OSRs as part of the OSR upgrade. (Added $5 / 20 / 91$ )

Repetition of OSRs 1.1.3 and 3.4.1 is not necessary. (Added 5/20/91)

Responsible audit personnel, requirements for keeping audit records, and responsibilities of Laboratory Safety Department staff are described below. (Revised 5/20/91)

5.5.1 Audit Personnel. The lead facility manager shall, on a quarterly basis, audit Neutron Multiplier operations for compliance with OSRs. Laboratory Safety shall appraise compliance with OSRs annually. (Revised $5 / 20 / 91$ )

Make assignments correspond to current organizational responsibilities. Remove extraneous material not part of a requirement. (Added 5/20/91)

5.5.2 Audit Records. The responsible management organizations are responsible for maintaining records of audits of the facility. The record file shall include copies of all current specifications and procedures as well as reports of deviations. Occurrences or observations needing prompt action shall be recorded, and the corrective action shall be documented. (Revised $5 / 20 / 91$ )

\subsubsection{The Laboratory Safety Department.}

The Laboratory Safety Department shall: 
(a) review all proposed revisions to the Safety Analysis Report and the OSRs for the Neutron Multiplier Facility;

(b) investigate abnormal occurrence violations of OSRs, review and concur on the measures to recover from an abnormal occurrence, and provide recommendations to preclude a recurrence;

(c) audit the facility operations at least twice a year for compliance with Criticality Safety Specifications. Radiation Safety Requirements are audited annually.

\subsection{Administrative Action in the Event an OSR is Not Met}

Failure to meet an OSR requires taking the action specified in the Corrective Action for that requirement. If an administrative control is not met, meet the requirement within 10 working days or shut down affected operations until compliance is achieved. (Revised 5/20/91)

The person finding the problem shall report the condition to line management immediately, and line management shall report the condition to safety management immediately. PNL management shall report and investigate the violation according to RL 5480.5, "Safety of Nuclear Facilities," and PNL-MA-7, Off-Nonmal Event Reporting System. (Revised 5/20/91)

Basis

RL 5480.5 and PNL-MA-7 reflect current requirements for reporting off normal events. Each Corrective Action statement tbat refers to Section 5.6 (a), (b) or (c) shall be modified to refer instead to Section 5.6. Special requirements apply to the administrative controls section of the OSRs since these do not contain corrective action statements.

\subsection{Records}

In addition to the records required by applicable regulations, PNL shall maintain records that demonstrate compliance with the Operational Safety Requirements for the Neutron Multiplier Facility. 


\section{Section 6 - Glossary}

Abnormal occurrence - An off-normal event, which may be an unusual occurrence as defined in PNL-MA-7.

Annually - Within a 12-month period of time that can extend to a maximum of 15 months when specified as an inspection or preventive maintenance period. The 12 -month period shall not be exceeded repeatedly.

Biennial - Within a 24-month period of time that can extend to a maximum of 30 months when specified as an inspection or preventive maintenance period. The 24 -month period shall not be exceeded repeatedly.

Biweekly - Once every two weeks. (Added 4/92)

Month(ly) - Within a 30-day period of time that can extend to a maximum of 45 days when specified as an inspection or preventive maintenance period. The 30-day period shall not be exceeded repeatedly.

NMF - Neutron Multiplier Facility.

Nuclear Chemistry Department - The Neutron Multiplier Facility is managed by the Nuclear Chemistry Department of the Materials and Chemical Sciences Center.

Nuclear Safety - A functional group within the Laboratory Safety Department, currently reporting to the Occupational and Radiological Safery Section.

Quarterly - Within a 3-month period of time that can extend to a maximum of 4 months when specified as an inspection or preventive maintenance period. The 3-month period shall not be exceeded repeatedly.

Radiation Protection - A PNL organization that reports to the manager of the Laboratory Safety Department.

Radiological Safety - The Radiological Engineering group within the Occupational and Radiological Safety Section of the Laboratory Safety Department.

Weekly - Within a 7-day period of time that can extend to a maximum of 10 days when specified as an inspection or preventive maintenance period. The 7-day period shall not be exceeded repeatedly. 



\section{Fuel Specifications}

Neutron Multiplier fuel is characterized by the following specifications (nominal values):

Fuel: uranium-aluminum alloy $(28 \mathrm{wt} \% \mathrm{U})$

Uranium enrichment: $93.2 \%{ }^{205} \mathrm{U}$

Clad wall thickness: 0.040 inch, 1100 aluminum tubing

Uncladded fuel diameter: 0.3 inch

Uncladded fuel length: 20.6 inches

${ }^{25} U$ content of each fuel element: 22.2 grams

Cladded fuel diameter: 0.40 inch

Cladded fuel length: 23.75 inches 
•

. 


\section{Distribution}

No. of

No. of

Copies

Copies

\section{ONSITE}

DOE Richland Field Office

C. E. Collantes P7-72 (uncontrolled)

Westinghouse Hanford Company

B. J. McMurray, L7-98 (controlled)

Pacific Northwest Laboratory

18 Controlled Copies

S. R. Bivins, P7-78

J. D. Bright, P7-08

L. C. Davenport, P7-78

L. R. Eberhardt, P7-70

D. M. Fleming, P7-01

R. E. Hawks, G4-07

D. B. Higby, P7-78

G. R. Hoenes, P7-78

L. V. Kimmel, P7-70

W. W. Laity, K2-50

E. A. Lepel, P8-08

D. E. Lucas, P7-78

C. L. Nelson, P8-20

D. E. Robertson, P8-01

A. J. Schilk, P8-01

J. W. Wald, K2-22

C. C. Wentz, P7-08

M. A. Williams, P7-70

16 Uncontrolled Copies

E. A. Lepel (10), P8-08

Publishing Coordination

Technical Report Files (5) 
